\title{
La Constitución Política enseñada a alumnos de educación superior no estudiantes de Derecho o ciencias afines: Un reto para la enseñanza
}

\author{
Carlos Andrés García Jiménez \\ cgarciaj@poligran.edu.co
}

Abogado egresado de la Universidad Colegio Mayor de Nuestra Señora del Rosario de Bogotá, especialista en Derecho Constitucional de la misma universidad. Diplomado en Investigación por la Asociación Colombiana para el Avance de la Ciencia y el Politécnico Grancolombiano, docente y coordinador del área de Derecho Público del Programa de Derecho, e investigador de la Institución Universitaria Politécnico Grancolombiano de Bogotá, consultor particular perteneciente al Colegio de Abogados Rosaristas de Bogotá.

Filiación institucional: Coordinador Área de Derecho Público, docente, investigador. Institución Universitaria Politécnico Grancolombiano.

\section{RESUMEN}

La Constitución Política de 1991 ordena el estudio del texto constitucional y el fomento de la participación en todas las instituciones educativas del país. La enseñanza de la constitución y el avance en competencias ciudadanas es esencial para el desarrollo de los individuos y los Estados. Es necesario plantear un modelo pedagógico diferente al tradicional en el que se manejan estos temas por personas o estudiantes adscritos a facultades de Derecho o ciencias afines en instituciones de educación superior, el cual deberá ser especialmente diseñado para ciudadanos del común. El nuevo modelo pedagógico debe buscar corregir las falencias del tradicional y ser efectivo frente al cumplimiento de los objetivos de la asignatura y el desarrollo de competencias ciudadanas como se describe en el texto.

\section{INTRODUCCIÓN}

El artículo 41 de la Constitución Política de Colombia determina: "En todas las instituciones de educación, oficiales o privadas, serán obligatorios el estudio de la Constitución y la Instrucción Cívica. Así mismo se fomentarán prácticas democráticas para el aprendizaje de los principios y valores de la participación ciudadana. El Estado divulgará la Constitución”.

De lo citado se desprende que, para el Constituyente del estado colombiano, es principio de importancia la formación de su población en conocimientos que a esta le permitan la participación, el desarrollo político y cívico individual dentro de la comunidad y hacia la comunidad. Validando esta hipótesis y además definiendo como central el aprendizaje, la enseñanza, la práctica de la Constitución Política y los mecanismos de participación ciudadana en nuestro Estado y en el mundo, como base de una adecuada convivencia

\section{PALABRAS CLAVE}

Constitución, competencias, ciudadanía, educación, Educación Superior, participación.

\section{ABSTRACT}

The Colombian Constitution of 1991 order the study of the text and the develop of participation skills in all the educative institutions of the country. The teaching of the Constitution and the advance in citizenship skills is the key for the develop of the human being in relation with the state. Is necessary to create a new teaching model, different to the traditional used in the Law Schools, to teach people that are not studying law or similar sciences. The new model must to be better to do the aims and develop skills. The keys of the model are the conclusion of the essay.

\section{KEY WORDS}

Constitution, College, Citizenship, Participation, Skills, Teaching, 
y construcción de los Estados, nos adentramos en el objeto central de este escrito.

La Constitución Política es la norma de normas, definida como: "El conjunto de reglas relativas a la atribución y al ejercicio del poder político" ${ }^{1}$. Adicionalmente, esta norma definida con un sentido ideológico determinado, basada en una noción de soberanía popular, "no puede ser sino democrática y liberal, democrática porque ella admite necesariamente que el poder procede del pueblo, liberal porque ella organiza necesariamente la división del poder y la protección de los derechos"2.

Lo anterior nos indica de forma indirecta una característica principal del texto normativo definido: el análisis y puesta en práctica de sus reglas y principios no interesa solamente a profesionales de la norma y la ley, a abogados y a jurisprudentes; su contenido es de la incumbencia de toda la ciudadanía y la población de un Estado, puesto que, la norma en cuestión será guía básica para su desempeño, su desarrollo individual, su contribución y participación en el avance y construcción del Estado mismo. Debemos decir entonces que la constitución política de los Estados tiene relación directa y primaria con todos los individuos pertenecientes a un Estado. Es por esto, que todos debemos conocerla y practicarla.

Percibir esta particularidad despierta en la academia una necesidad seria e importante: la norma constitucional ha sido estudiada tradicionalmente en la universidad por comunidades afines al Derecho o a la política; las metodologías de estudio y enseñanza se han aferrado centralmente a estas áreas y a sus modos tradicionales de transmisión del conocimiento, olvidando al público diverso al que deben dirigirse. El resultado de lo anterior ha sido un desinterés latente del alumno-ciudadano por esta temática, una sensación de verse sometido al trabajo con conocimiento poco útil o que no le pertenece, lo que en última instancia redunda directamente en su interés frente al Estado y la comunidad. Es necesario pensar entonces, en una nueva metodología pedagógica que nos permita introducir correctamente a toda una comunidad universitaria, ciudadanos y población de un Estado, en el estudio de la norma.

\section{¿Por qué es necesaria una metodología pedagógica distinta?}

Nos enfrentamos a un problema particular. ¿Cómo enseñar sobre la constitución política, las prácticas y competencias ciudadanas, a sujetos pertenecientes a instituciones de educación superior que no estudian Derecho o ciencias afines? Tal como se dijo, la respuesta hasta el momento ha sido la metodología tradicional, la misma usada para la enseñanza de esta área del conocimiento, a sujetos que se encuentran dentro del aprendizaje y aleccionamiento en ciencias afines y directamente relacionadas (Derecho, Ciencias Políticas, Relaciones Internacionales, etcétera). En las aulas del mundo, la Constitución se enseña por igual a todos los ciudadanos, principalmente a partir de la exposición magistral, la lectura y el análisis de los conceptos.

Además de presentar esta metodología aplicada a ciencias afines, inconvenientes y problemas, -situación que observaremos más adelante-, podemos concluir que, en el caso que nos ocupa (la educación en ciudadanía, participación y Constitución a la población de instituciones de educación superior no vinculada a facultades de Derecho o ciencias afines), el tema se hace todavía más difícil y es necesaria una metodología distinta.

Tres ejes centrales del asunto pueden explicarlo:

\section{- La enseñanza de las temáticas busca objetivos dife-}

rentes. Aunque los conceptos, nociones y saberes que se usan y se transmiten son semejantes en muchas ocasiones, tanto en el estudio de ciencias afines como en el del ciudadano del común, sus objetivos distan de ser iguales. En el primero podríamos decir que se busca inicialmente el aprendizaje y el dominio de los temas constitucionales con miras a la aplicación técnica y científica de la norma; mientras que en el segundo caso nos referimos a algo más terrenal, más complejo, el papel de las generaciones futuras y su "derecho de vivir en una sociedad mucho más pacífica, democrática y justa"; además de "el deber de contribuir a la construcción de dicha sociedad ${ }^{3}$.

- El perfil del alumnado. Debe observarse que mientras en las ciencias afines encontramos estudiantes familiarizados e interesados por la materia, los conocimientos y la metodología pedagógica usada, en los demás casos, de ciencias no pertenecientes a estas, debemos

1 CEPEDA, Manuel José y DUHAMEL, Oliver. Las Democracias. Entre el Derecho Constitucional y la Política. Tercer Mundo Editores. Primera Edición. 1997. Pág. 352.

2 Ibíd., Pág. 353

3 Ministerio de Educación Nacional. Estándares Básicos de Competencias en Lenguaje, Matemáticas, Ciencias y Ciudadanas. Primera Edición. Bogotá: Ministerio de Educación Nacional, 2006. 
enfrentarnos a estudiantes que en la gran mayoría de los casos nunca han estudiado temas ni siquiera cercanos; que además, en numerosas ocasiones no tienen el más mínimo interés o nivel de preferencia y que, por último, se encuentran totalmente lejanos de la metodología tradicionalmente utilizada.

- Las competencias que se buscan implementar en los estudiantes son diferentes. Visto lo anterior, teniendo claro que los objetivos son diferentes en el caso de las ciencias afines, y en el de los demás ciudadanos -estudiantes de instituciones de educación superior- que se enfrentan a este conocimiento, debemos percatarnos también de que las competencias que buscamos desarrollar en una y otra experiencia varían sustancialmente.

\section{Problemas dela metodología tradicional de la enseñanza del Derecho y la Constitución frente a los estudiantes de ciencias afines y los estudiantes de ciencias no relacio- nadas}

El método tradicional más acentuado en la academia para la enseñanza del Derecho y el conocimiento relacionado, que se encuentra en estos momentos en franca discusión y replanteamiento, es el de la clase magistral. Se define esta como "la presentación de un tema lógicamente estructurado con la finalidad de facilitar información organizada siguiendo criterios adecuados a la finalidad pretendida. Esta metodología se centra fundamentalmente en la exposición verbal por parte del profesor de los contenidos sobre la materia objeto de estudio" ${ }^{4}$. La metodología citada, en los términos conceptuados tiene graves desventajas para el aprendizaje de estudiantes de ciencias afines, y mucho más aún para estudiantes de ciencias o artes, no relacionados:

- Ofrece poca participación al estudiante, es decir, justamente carece de uno de los valores principales que se buscan inculcar, cuando de formar al ciudadano del común (no abogado, o estudiante de Derecho) en constitución, participación y ciudadanía se trata.

- La clase tiende a tornarse teórica, situación que observaremos es perjudicial para nuestros fines.
- La clase tiende a tornarse teórica, situación que observaremos es perjudicial para nuestros fines.

- Hace que el estudiante se sienta alejado de temas que aparentemente se quedan en la palabra, es decir, que no tienen aplicación práctica; el receptor no los siente como propios e importantes y, por tanto, no se interesa o no sabe cómo utilizarlos efectivamente. El alumno en muchas ocasiones se queda en la recepción de datos por lo que se pierde el objetivo final: la creación de competencias ciudadanas prácticas.

- Las competencias que se buscan crear en los alumnos-ciudadanos son casi en su totalidad de carácter aplicativo, o al menos teórico-práctico, situación que se contradice con el método magistral, donde el estudio aplicado de saberes se reduce.

- Muchos alumnos universitarios, adscritos a otras escuelas del saber o del conocimiento no se encuentran familiarizados con esta metodología. Internarlos en la misma, con un tema que parece ajeno a sus estudios hace la temática extraña y menos atractiva.

Lo anterior nos describe la problemática frente al punto de partida del método tradicional del Derecho (la cátedra magistral). Pero aquí no puede terminar nuestro análisis. Si observamos otros elementos reiterativos y constantes en la metodología y la modalidad usada para la enseñanza de la Constitución y el Derecho, encontraremos otras cosas por revisar.

Las expertas en el tema, Ana Giacometto Ferrer y Alicia García González identifican cuatro problemas en la enseñanza actual del Derecho ${ }^{5}$ :

- La enseñanza del Derecho es teórica. La metodología tradicional de enseñanza del Derecho mediante la clase magistral se ocupa del entendimiento y dominio de teorías y conceptos. Forma simple de enseñanza que desvincula lo teórico de lo práctico, dejando como consecuencia, que en muchas ocasiones el estudiante no aprenda a vincular un lado con el otro. Lo anterior sumado a una poca participación del estudiante, poca retroalimentación entre los sujetos en juego, el no atender al ritmo individual de cada alumno, el no controlar el progreso del estudiante y no facilitar el aprendizaje autónomo ${ }^{6}$, hace que la clase teórica como base cen-

4 DÍAZ, Mario de Miguel. Metodologías de enseñanza y aprendizaje para el desarrollo de competencias. Madrid: Alianza Editorial. Primera Reimpresión. 2006. Pág. 44.

5 GIACOMETTO, Ana y GARCÍA, Alicia. Crisis en la Enseñanza del Derecho. Bogotá: Ediciones Librería del Profesional. Primera Edición. 2000. Págs. 47 a 54.

6 DÍAZ, Mario de Miguel. Op. Cit. Pág. 45. 
tral del método, se torne inconveniente para la finalidad buscada.

- La enseñanza del Derecho comporta una exagerada exigencia de "memoria pura". Comúnmente se ha relacionado el Derecho con la acumulación de datos. Esto lastimosamente se ha transmitido a la enseñanza. En muchas ocasiones es enseñado como una receta de cocina, donde se toman datos que simplemente se deben aplicar en ciertas cantidades a unos hechos determinados.

\section{-El plan de estudios no está debidamente estructura-}

do. No existe claridad y en muchos casos consecuencialidad entre los contenidos de los planes de estudios, las competencias y los objetivos que se van a desarrollar. Esta problemática se fortalece cuando programas de estudio de Derecho, con objetivos diferentes, son calcados para ser dictados a estudiantes de educación superior de otras facultades no afines, cuyos objetivos e intereses son distintos.

Sumado a lo anterior, David Mathews nos muestra otra situación perjudicial presente en la enseñanza de la Constitución, en este caso una más circunscrita al problema planteado:

- La forma como una generación enseña explícitamente a otra sobre política y ciudadanía puede ser tan derrotista como la lección implícita de la impotencia y el escepticismo. Triste e irónicamente, los jóvenes pueden aprender a no ser ciudadanos. La definición generalizada de la política como un combate entre políticos, mediado por la mecánica del gobierno, tiene un efecto debilitador en la educación política de los estudiantes. Bajo esta interpretación los ciudadanos tienen realmente muy poco que hacer. La ciudadanía es descrita casi siempre como un deporte de espectadores. (Hay que recordar las clases sobre "cómo se hacen las leyes"). Los estudiantes aprenden lo que hacen otras personas -los presidentes, los gobernadores, los congresistas, los jueces-.Como la mayoría de ellos no esperan desempeñar estos papeles, lo que aprenden a la larga es que la política es un mundo aparte, separado de ellos y de su vida diaria. Los ciudadanos aparecen ante todo como observadores pasivos de otros. Aun si se enseña a la gente a mirar con ojo crítico, la implicación sigue siendo que los ciudadanos no son más que consumidores informados. Cuando los jóvenes de este país asimilan el comportamiento cívico en estos términos pasivos, no habrá exhortaciones al deber capaces de movilizarlos a participar activamente como ciudadanos ${ }^{7}$.

Lo anterior nos demuestra que existen problemas metodológicos importantes en la forma como se enseña el derecho y la Constitución hoy en día, tanto en el medio de las ciencias afines a las temáticas, como en la enseñanza de la Constitución a la ciudadanía en general (estudiantes de educación superior), tema en particular que nos ocupa 8 .

\section{CONCLUSIÓN.}

\section{Bases para una nueva metodología pedagógica para la enseñanza de la Constitución a estudiantes de ins- tituciones de educación superior no inscritos en facul- tades de Derecho o ciencias afines}

Lo ya visto en los apartes anteriores nos indica dos asuntos centrales:

- La metodología pedagógica tradicional del Derecho no tiene funcionalidad o efectividad para la enseñanza de la Constitución, y el desarrollo de competencias ciudadanas en estudiantes de educación superior pertenecientes a Facultades ajenas al Derecho o ciencias afines.

-La metodología y la modalidad de enseñanza tradicional de la Constitución y el Derecho, presentan falencias en estas facultades y en ciencias afines, las cuales se afianzan y profundizan negativamente en el caso de la enseñanza de la Constitución y en la creación de competencias ciudadanas en estudiantes no pertenecientes a estas ramas del conocimiento.

Aceptado lo anterior, es totalmente clara la necesidad planteada desde el inicio en el sentido de optar por un modelo pedagógico novedoso que responda al objetivo y competencias a desarrollar en la enseñanza de la Constitución y las Instituciones Políticas del Estado, a

7 MATHEWS, David. Política para la gente. Medellín: Editorial Dike. Reimpresión de la Segunda Edición. 2006. Pág. 60. 8 Debemos recordar en este punto cómo es definitiva la diferencia entre los objetivos y las competencias que se van desarrollar entre la enseñanza de la constitución en una facultad de Derecho y en un salón de estudiantes de otras facultades no afines al Derecho. 
alumnos de educación superior no estudiantes de Derecho o ciencias afines.

- La metodología y la modalidad de enseñanza tradicional de la Constitución y el Derecho, presentan falencias en estas facultades y en ciencias afines, las cuales se afianzan y profundizan negativamente en el caso de la enseñanza de la Constitución y en la creación de competencias ciudadanas en estudiantes no pertenecientes a estas ramas del conocimiento.

Aceptado lo anterior, es totalmente clara la necesidad planteada desde el inicio en el sentido de optar por un modelo pedagógico novedoso que responda al objetivo y competencias a desarrollar en la enseñanza de la Constitución y las Instituciones Políticas del Estado, a alumnos de educación superior no estudiantes de Derecho o ciencias afines.

Será entonces la manera adecuada de cerrar este escrito plantear las bases para el desarrollo de un modelo metodológico pedagógico para la enseñanza de la Constitución y el desarrollo de competencias ciudadanas en estudiantes de educación superior no adscritos a facultades de Derecho, ciencias o artes afines.

El profesor Alejandro Sánchez de manera alterna ve la expresión política de la juventud y muestra un nuevo camino para motivar a los jóvenes en la participación y en la construcción de Estado:

Pensar las formas de acción política de los jóvenes a partir de los referentes que estructuraron nuestras formas de entender lo político', suele conducir a descalificaciones apresuradas. Se les juzga por su apatía e indiferencia ante los emblemas de la democracia moderna (la razón, el argumento, el consenso, el debate), sus rituales y procedimientos. Se les concibe como sujetos anómicos, sin proyectos, cuando en realidad es la política la que dejó de operar a partir de proyectos y experimentas transformaciones profundas en los lenguajes a partir de los que esta se configura y se integra a nuestra vida diaria. Como nos lo recuerda Beatriz Sarlo, el proyecto moderno fundó la política en las competencias lecto-escriturales, en el lenguaje escrito y en el libro, representaciones por excelencia de la Ilustración y condiciones para la ciudadanía.
Y con la escritura dio vida a una política de los manifiestos, de las proclamas, de los principios, de los códigos y -recordará Habermas- de la prensa. Asistimos hoy, como lo confirman las más recientes investigaciones sobre consumo cultural en América Latina, a un repliegue de la lectura y a un predominio creciente de lo audiovisual. A esto debemos sumar la progresiva mediatización de la cultura, proceso a través del cual los medios de comunicación se convierten en escenarios fundamentales en la producción, circulación y apropiación de sentidos, significados, maneras de ver y entender el mundo. Ambos procesos suponen cambios en las gramáticas desde las que se piensa y se actúa políticamente. Cambios que producen especial resonancia en los jóvenes 9 "Bloggers, adictos al messenger o simples consumidores mediáticos, los jóvenes bien podrían estar creando las nuevas gramáticas de lo político"10.

A estas nuevas formas de observar la educación en participación política, ciudadanía y Constitución también se refiere Rosa Marí Ytarte.

La educación de la ciudadanía, además de cómo estatus y derecho, supone la apuesta por una pedagogía "pedagogía abierta". En este sentido amplio la ciudadanía es competencia de la educación y se ocupa principalmente de garantizar el pleno acceso al espacio social de todos y cada uno de los sujetos de la educación, pero también de construir, de crear ese espacio común a través de la cultura. La idea de ciudadanía se relaciona con tres dimensiones de lo educativo (Sáez, 2004): con el conocimiento de los asuntos públicos de la comunidad política; con las actitudes vinculadas al sentido cívico y con las competencias técnicas relativas a la participación política. Pero además, una pedagogía abierta sería aquella que puede construir la ciudadanía desde unas narraciones sobre lo humano globales e integradoras $^{11}$.

Desde este punto de vista, serían principios de base para el planteamiento de un modelo pedagógico (metodología), válido y efectivo para la formación en Constitución y ciudadanía de sujetos vinculados a instituciones de educación superior, no estudiantes de derecho o ciencias afines:

9 SÁNCHEZ, Alejandro. ¿Desde dónde hacen política los jóvenes?: Una Pregunta para jóvenes y ex jóvenes. En: El Poli. Bogotá: No 14. Noviembre, 2006. Pág. 21.

10 Ibíd. Pág. 21

11 YTARTE, Rosa Marí. ¿Culturas contra ciudadanía?: Modelos inestables en educación. Barcelona: Editorial Gedisa. Primera Edición. 2007. Pág. 190 
- La apropiación por el modelo de las nuevas formas de transmisión del conocimiento y la información, los nuevos caminos de comunicación de los jóvenes. La metodología pedagógica indicada deberá usar como herramientas los lenguajes y los medios con mayor difusión y fuerza actualmente entre las personas. De esta forma se logrará llegar con la información y desarrollar las competencias planeadas en los alumnos. Será indispensable que el modelo ideado tenga como base de partida medios actuales como el internet (y las sub-herramientas que este incluye), la tecnología, los medios audiovisuales, el trabajo con la información transmitida por los medios audiovisuales de comunicación, la música, el arte, entre otros medios de comunicación que los jóvenes frecuentan, prefieren y entienden. Si la metodología planteada utiliza las mismas herramientas y lenguajes con los que se comunican las personas en la actualidad, es seguro que su efectividad será mucho más alta.

\section{- La inclusión en el modelo de las vías de participa- ción e identificación dentro de la comunidad de los jóvenes. Deberá tenerse en cuenta que hoy en día los sujetos se identifican y participan a través de medios distintos a los tradicionales. Los grupos de preferencia, de interés o de consenso, en muchas ocasiones ya no están delimitados por una inclinación política. Según Sánchez:}

Nos enfrentamos con un universo de prácticas muy diversas, en las que se ponen en escena apuestas (no proyectos) de transformación de la cotidianidad, desde lo micro, que en muchas ocasiones desprecian abiertamente los escenarios formales de lo político. Skin heads, anarcos, punketos, hoppers, cristianos, etc. se convierten en lugares desde los cuales construir identidades alternativas, visibilizar y discutir asuntos cotidianos $^{12}$.

Agregaría al caso concreto colombiano grupos como las diferentes etnias raciales, los grupos creados por la estratificación social, los grupos de diversas orientaciones sexuales, etcétera. El modelo pedagógico planteado deberá enfocar la participación desde estos medios novedosos de interacción social: cómo participar y, a través de qué herramientas, desde los grupos sociales constituyentes hoy de la Nación, del Estado. De esta

12 SÁNCHEZ, Alejandro. Óp. Cit. Pág. 21. manera la ciudadanía y la participación no se construirá en las aulas a partir de grupos sociales tradicionales (cohesionados a partir de una ideología política heredada, por ejemplo, partidos políticos); se hará a partir de las posiciones que han escogido ocupar los estudiantes dentro de un grupo social determinado y dentro de la comunidad.

- La enseñanza de la participación, los valores éticos que guían la participación y la técnica para participar con base en los medios ya mencionados (nuevas formas de transmisión del conocimiento y de comunicación, nuevas vías de participación e identificación), en un marco dialéctico diverso, integrador e incluyente. El modelo planteado deberá estar inmerso en un ambiente de diversidad e inclusión. Ya que la participación será guiada desde los nuevos medios de interacción social, será necesario que exista espacio de expresión y participación en el modelo para todos esos grupos, sin ningún tipo de discriminación entre ellos.

\section{BIBLIOGRAFÍA}

-Cepeda, Manuel José y Duhamel, Oliver. Las democracias: Entre el Derecho Constitucional y la política. Primera Edición. Bogotá: Tercer Mundo Editores, 1997. -ConstituciónPolíticadeColombia.Disponibleen:<http:// www.secretariasenado.gov.co/leyes/CONS_P91.HTM> -De Miguel Díaz, Mario (Coordinador). Clases Teóricas. En: De Miguel Díaz, Mario. Metodologías de enseñanza y aprendizaje para el desarrollo de competencias: Orientaciones para el profesorado universitario ante el espacio europeo de educación superior. Primera Reimpresión. Madrid: Alianza Editorial, 2006. - Ferrer, Ana y García, Alicia. Crisis en la enseñanza del Derecho. Primera Edición. Bogotá: Ediciones Librería del Profesional, 2000. -Mathews, David. Política para la Gente. Reimpresión de la Segunda Edición. Medellín: Biblioteca Jurídica Diké, 2006. ISBN 0-252-02088-X -Ministerio De Educación Nacional. Estándares Básicos de Competencias en Lenguaje, Matemáticas, Ciencias y Ciudadanas: Guía sobre lo que los estudiantes deben saber y saber hacer con lo que aprenden. Bogotá: Ministerio de Educación Nacional, 2006. -Sánchez, Alejandro.“¿Desde dónde hacen política los jóvenes?: Una pregunta para jóvenes y ex jóvenes”. En: Revista El Poli. No 14, noviembre, 2006. -Ytarte, Rosa Marí. ¿Culturas contra ciudadanía?: Modelos inestables en educación. Primera Edición. Barcelona: Editorial Gedisa, 2007. 